\title{
Research on Oral English Flipped Classroom Project- based Teaching Model Based on Cooperative Learning in China
}

\author{
Xiaoyan Fan \\ Zhoukou Normal University
}

\begin{abstract}
Project-based teaching method is a new task-driven and project-oriented teaching mode, it has become an effective means of practical teaching. However, in the process of project-based teaching, there are also some problems, such as difficult to control classroom teaching time and so on. As a new teaching mode under the background of informationization, flipped classroom can fully realize students' principal position in learning activities. Based on the applied research of English oral flipped classroom teaching, the concept of flipped classroom teaching is integrated into project-based teaching in this paper. By using flipped classroom and cooperative learning, students can reduce the time of teachers' classroom instruction and increase the time of students' participation in project practice through independent learning of network courseware before class, it can make up for the shortcoming of classroom teaching time in project-based teaching.
\end{abstract}

\section{Keywords}

Flipped Classroom • Oral English • Project-Based Teaching • Cooperative Learning

Zhoukou Normal University, Zhoukou 466001, China. Email: 121743143@qq.com

Citation: Fan, X. Y. (2018). Research on Oral English Flipped Classroom Project-based Teaching Model Based on Cooperative Learning in China. Educational Sciences: Theory \& Practice, 18(5), 1988-1998. http://dx.doi.org/10.12738/estp.2018.5.098 
Fan / Research on Oral English Flipped Classroom Project-based Teaching Model...

With the continuous development of social economy and information technology, international cultural exchanges and economic exchanges have become increasingly close. As a universal language in the world, English is important to social development. However, there are some difficulties and challenges in English teaching. The traditional and backward teaching mode and the differences of students' abilities lead to the low level of English teaching now.

As a new teaching mode, flipped classroom can effectively improve the efficiency of English teaching (Gilboy, Heinerichs, \& Pazzaglia, 2015). It refers to adjusting the time allocation inside and outside the classroom in the teaching activities, and giving full play to the dominant position of students in learning.

Cooperative learning (Balkcom, 1992) refers to a mutual aid learning mode with clear division of responsibilities. It can help students actively develop their subjective initiative and complete their learning tasks together. Cooperative learning can stimulate students' sense of collective honor, and then better accomplish collective tasks. Students can meet personal interests and realize personal ideals while fulfilling tasks.

Project-based teaching method tries to combine theory with practice organically by implementing a series of complete teaching projects (Turnbull, 2010). It takes task-oriented teaching activities and training students' professional skills as the primary task of teaching. As the project-based teaching method no longer focuses on teachers and emphasizes students' autonomous learning, the flipped classroom is a teaching method suitable for project-based teaching. At the same time, cooperative learning can promote the effect of flipped classroom teaching. The research on oral English flipped classroom project-based teaching based on cooperative learning has important social value and educational significance.

\section{Preliminaries}

\section{Cooperative learning}

Cooperative learning originated from American society in the 1970s, and in the 1980 s it formed a practical teaching theory (Nelson, 1996). As cooperative learning would create an atmosphere of classroom teaching, it can improve students' academic performance and personal ability. Cooperative learning is a structured and systematic way of learning, and it consists mainly of 2-6 students who form learning groups to complete learning tasks in groups. Therefore, cooperative learning mainly focuses on cooperation and help to achieve learning activities. Through this learning way, everyone's personal ability can be improved while completing group goals and tasks. The formation and development of cooperative learning is based on the theory of goal structure and it has certain educational functions. It can cultivate students' cooperative spirit, competitive spirit, communicative ability and innovative spirit. At the same time, teachers are required to grasp students' subjective concepts, innovate teaching concepts and methods, and they should use information synchronization and thinking synchronization to improve teaching quality and efficiency.

Cooperative learning is not only a teaching mode, but also a teaching strategy (Silverman, 2011). The process of cooperative learning can be basically divided into three stages: grouping and task delivery, skill explanation and task subdivision, and member collaboration in task completion and feedback. The success of cooperative learning depends on the complementarity of team members' abilities and the sharing of resources. 
Fan / Research on Oral English Flipped Classroom Project-based Teaching Model...

Specifically, cooperative learning is closely related to the following four principles: cognitive principle, interdependence principle, motivation principle and sociological principle (Teng \& Luo, 2015).

\section{Project-based Teaching}

Compared with the traditional teaching method, the project-based teaching method has changed a lot in the aspects of educational idea, teaching goal, teaching environment, teaching process and teaching means. Projectbased teaching no longer focuses on teachers, and it emphasizes students' autonomous learning. It has changed the pattern of separation between theoretical teaching and practical teaching in traditional teaching.

Under the guidance of constructivism (Chen, Burry-Stock \& Rovegno, 2000), the project-based teaching method re-integrates the teaching contents of the traditional discipline system through the form of projects. The knowledge content to be mastered is divided into several relatively independent teaching projects, each of project has a certain task. In the process of teaching, teachers need to decompose the project and demonstrate it appropriately. Then, students should work in a limited time to complete the project task. Through direct participation in the process of project implementation, students understand every link of the project, they summarize and evaluate the results achieved after the completion of the project. They can grasp the key knowledge points and the difficult points in the whole project implementation process, and ultimately realize the learning style of "learning by doing". Project-based teaching has the typical characteristics of practicality and experience. It pays attention not to the final results of the project, but to the ways for students to acquire knowledge, skills and solve problems through the implementation of specific projects. In the process of completing the project, project-based teaching could cultivate students' sense of responsibility and team work ability, students' ability to complete complex work across disciplines and fields, and students' ability to deepen and expand their knowledge independently.

The choice of teaching project in project-based teaching method comes from engineering practice. Each project has different learning objectives from other projects. Many interrelated and interacting knowledge points can be systematically processed and integrated into one project for teaching. In the process of teaching design, it would embody the student-centered teaching organization. Teachers do not simply teach knowledge in class, and students are no longer passively learning according to the fixed process designed by teachers. Teachers should give full consideration to students' interest in learning and play to students' initiative, enthusiasm and creativity, which will ensure that every student should take part in the completion of work tasks. Students should participate in the design of learning process in the process of completing work tasks, acquire more knowledge and broaden their horizons by constantly finding and solving problems. Teachers should give appropriate guidance to students' problems in appropriate time. Project-based teaching method stimulates students' curiosity, attracts students' attention and enhances their learning initiative by letting each student directly participate in the implementation of the project. By completing the project tasks, students can sort out a large number of new knowledges, which makes the understanding and memory of knowledge easier and lasts longer. So, it can improve teaching efficiency greatly. 


\section{Flipped classroom}

The first application of flipped classroom in classroom teaching is the teachers in Colorado Woodland Park High School (Mclaughlin et al., 2014). They made a subversive attempt at the traditional classroom. At first, they just used screen capture software to record PowerPoint presentation broadcasting and explaining, and uploaded the video to the network. They only wanted to make up for the students who delayed the class. But they soon realized that all students could benefit from this video teaching method. Instead of spending time in class to listen to teachers' explanations of conceptual knowledge or operational methods, students could complete the process of knowledge transmission by watching videos at home. This kind of flipped classroom overturns the traditional classroom teaching mode. Teachers provide learning resources mainly in the form of teaching videos. Students complete watching and learning of learning resources such as teaching videos after class with the assistance of information technology. The time in class is mainly completed by teachers and students together to perform research, interaction and other activities.

The teaching mode of flipped classroom is mainly that students learn by themselves through watching the video of the teachers in class, so that students can make effective use of educational resources for learning (Herreid \& Schiller, 2013). Based on the flipped classroom teaching mode, students can make better use of the teaching time in the classroom, and pay more attention to the learning link. At the same time, in the teaching mode of flipped classroom, teachers no longer need to use classroom time to explain basic knowledge, and students can use pre-class time to learn. So teachers can teach more knowledge needed by students in class time.

There are similarities between the teaching methods of flipped classroom and hybrid learning. These new learning methods can make students' learning more flexible, enhance students' participation, and change teachers' teaching content. Flipped classroom has the characteristics of short and concise teaching video, clear teaching information, convenient learning process. The realization of flipped classroom needs a certain practical process. Firstly, we should establish a firm belief in educational reform. Secondly, teachers should have a high level of education information literacy, which are able to accurately grasp the time point of flipped classroom, and do a good job in the transformation from "leader" to "guide".

\section{Present situation analysis of spoken English teaching}

At present, the problems in oral English teaching are mainly included two aspects: teaching mode and students' learning attitude. Firstly, teaching mode and teaching idea in China are relatively backward compared with advanced countries because of the late start of teaching research. In the traditional teaching mode, teachers are the main body of teaching, students are in the position of passive reception of oral English knowledge, and teachers pay more attention to the study of theoretical knowledge, but they ignore the cultivation of students' practical application ability. Therefore, there are some problems in students' oral English learning in China. Traditional teaching modes and concepts will affect students 'interest in learning and subjective initiative, and then it will reduce the effectiveness of oral English teaching. Secondly, because of the differences between the basic and learning ability of spoken English, there will be great differences between students' spoken English 
Fan / Research on Oral English Flipped Classroom Project-based Teaching Model...

proficiency, which will affect students' learning enthusiasm and learning information. The traditional teaching model cannot meet the learning needs of each student, so there is a big difference between students' academic performance and oral ability. Moreover, it causes that students' interest and enthusiasm in learning English is not high, and it seriously limits their oral English ability.

According to the author's rich experience in oral English teaching, we found that there is still a lack of attention and effective methods to cultivate students' oral English ability. There are the following specific problems:

(1) College English curriculum does not emphasize the importance of oral English teaching. Nowadays, college English curriculum is mainly composed of reading and writing courses, listening and speaking courses account for a relatively low proportion, and oral textbooks are limited in scope. Due to the large number of students in English classes and the difficulty of interaction, students with limited listening and speaking training have fewer opportunities to express themselves oral English ability.

(2) Students' language foundation is weak and language input is not enough. Students are subjectively passive and neglectful of the importance of oral ability, lack of self-confidence and fear of making mistakes, which makes oral classroom interaction is not high, and students' language ability has not been exercised and improved. Secondly, the language foundation of college students is weak, and there is a big gap between the individual language foundation, which is mainly reflected in phonetics, grammar, vocabulary and so on. Therefore, the oral expression ability of students is limited.

(3) Lack of understanding of multimedia teaching and unreasonable use of multimedia courseware. In recent years, the application of multimedia courseware in College English teaching has become the mainstream, and oral English teaching is no exception. However, in the practice of oral English teaching, multimedia teaching does not show its obvious advantages over traditional blackboard teaching. Some teachers are even constrained by multimedia courseware; thus, classroom interaction is affected. Courseware is lack of new ideas, which will result in lower class enthusiasm. Some teachers used multimedia courseware as the leading part of oral English teaching, but the follow-up enlightenment is not enough, which causes students to lack reflection and in-depth thinking after watching relevant video and phonetic materials. And multimedia courseware does not play a role in paving the way for the later listening and speaking training. So, the effect of multimedia courseware in assisting oral English teaching is not obvious.

Aiming at the above problems, in order to understand whether the cooperative learning-based oral English flipped classroom can stimulate students 'interest in learning, improve students' learning ability, and then cultivate students' awareness and ability of autonomous learning, more than 1000 students were interviewed. Surveys and interviews show that students have a high recognition degree for the reversal of oral English class, and it is generally believed that it can improve their autonomous learning ability and oral English performance. In the process of investigation, we know that teachers are no longer the leader of learning activities under the flipped classroom model, but they play the role of guides. Students will use the knowledge they have learned to communicate and interact with each other. 


\section{Application of flipped classroom based on cooperative learning in project-based teaching}

\section{Necessity}

The problems involved in each project in project-based teaching, big or small, have the characteristics of comprehensiveness and openness (Pu, Zhang, Fang, \& Zhi, 2017). Comprehensive means that project-based teaching integrates theoretical knowledge and practical operation into the project, and the implementation of each project contains a variety of knowledge and skills. Openness means that it is not only limited to books, but also from a certain point of view. The problems it involves are very practical, constantly changing and developing, and it can be analyzed from different angles.

In addition, project-based teaching pays attention to the combination of theory and practice, but it does not relax the grasp of basic theory. Every project should consider the rationality of the topic selection and the preparation of the prior knowledge. In order to complete the teaching task of project-based teaching within the limited class hours, it is a good choice to integrate the concept of flipped classroom teaching into project-based teaching.

First of all, flipped classroom is a very practical teaching method, it can use various advanced teaching methods to enhance the teaching effect. For more easily understood knowledge points, students can be taught through simple teaching courseware by teachers. For more abstract and difficult to understand or describe knowledge points, we can consider using two-dimensional or three-dimensional animation technology to show them vividly, concretely and vividly.

Secondly, there are many teaching contents in project-based teaching. All knowledge points involved in each project will obviously make the classroom time insufficient. Teachers need to select the important teaching content as much as possible before class to ensure that students' classroom practice operation time is sufficient. However, the project-based teaching which incorporates the flipped classroom greatly prolongs the learning time of students. Students can choose and arrange the learning content according to their own conditions. The sharing network resources also provides students to a large number of knowledge sources. Students can choose to read relevant materials on the network according to their own actual situation. They need not spend any more time to learn the knowledge points they are already familiar with, as long as they read the knowledge points they are not clear about.

Thirdly, project-based teaching incorporating the flipped classroom will break the limitation of traditional teaching methods on students' learning space and progress. Students can choose to watch teaching courseware in a comfortable environment. They can adjust their learning schedule according to their mastery of knowledge and understanding of knowledge, and they can flexibly grasp the learning place and time allocation according to their own state to improve learning efficiency. The fruitful face-to-face interactive learning and personal participation in project practice are the most important application value of the flipped classroom in projectbased teaching. 
Fan / Research on Oral English Flipped Classroom Project-based Teaching Model...

\section{Feasibility}

Firstly, with the development of network technology and computer technology, advanced information technology and software support have realized the transmission of teaching courseware through network. Universal multimedia tools are used to process classroom teaching content, digital teaching resource with abundant pictures and texts can be formed. All students in relevant majors can use the Internet to enjoy courseware resources made by teachers.

Secondly, the rapid changes in teaching methods are changing the teaching concept. Students become the core of teaching, learning materials, strategies and methods suitable for students' characteristics can be provided to different students through using the network. Network is not only an assistant tool for teachers to teach, but also an important means to transfer teaching content, and it is an important cognitive tool for students to explore, discover and learn.

Thirdly, project-based teaching enables students to master relevant knowledge points by directly participating in the implementation of the project. Before participating in the specific implementation of the project, it is necessary to understand the specific steps of the project implementation. It is best to visit the actual implementation site of the project, but it is difficult for most students. Flipped classroom can solve this problem to a certain extent. It can directly reproduce the real working process to the students through live video, which can let the students know the content of project-based teaching directly before class, and save the time for teachers to explain in class.

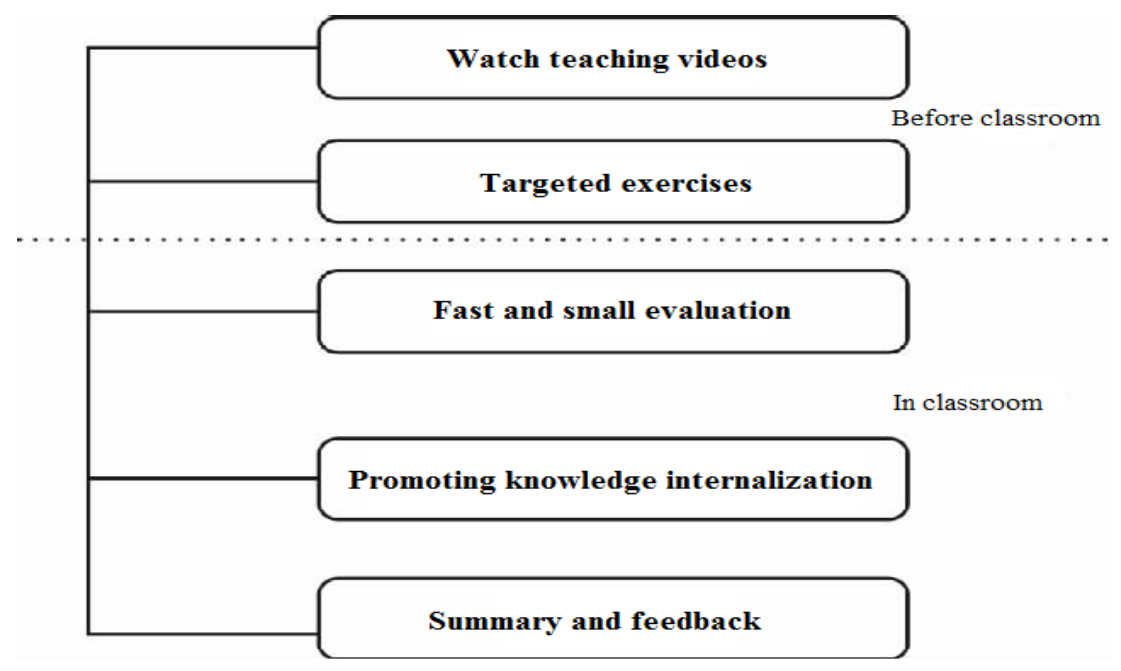

Figure 1. Structure model of flipped classroom

\section{Design of teaching model}

The flipped classroom enhances the teaching effect by reversing the process of knowledge imparting and internalization in traditional classroom. After many years of teaching accumulation, we summarized the 
implementation structure model of flipped classroom, which briefly describes the important links in the implementation process of flipped classroom. The structure model is shown in Figure 1.

Based on the basic teaching structure of flipped classroom model, we can consider applying flipped classroom to project-based teaching practice. By using the new project-based teaching method, students 'learning efficiency can be improved and a more student-centered project-based teaching model can be constructed. Therefore, on the basis of the traditional flipped classroom model, we try to design a project-based teaching model based on the flipped classroom. The new model consists of teachers' teaching process structure and students' learning process structure.

The teachers' teaching process structure is shown in Figure 2.

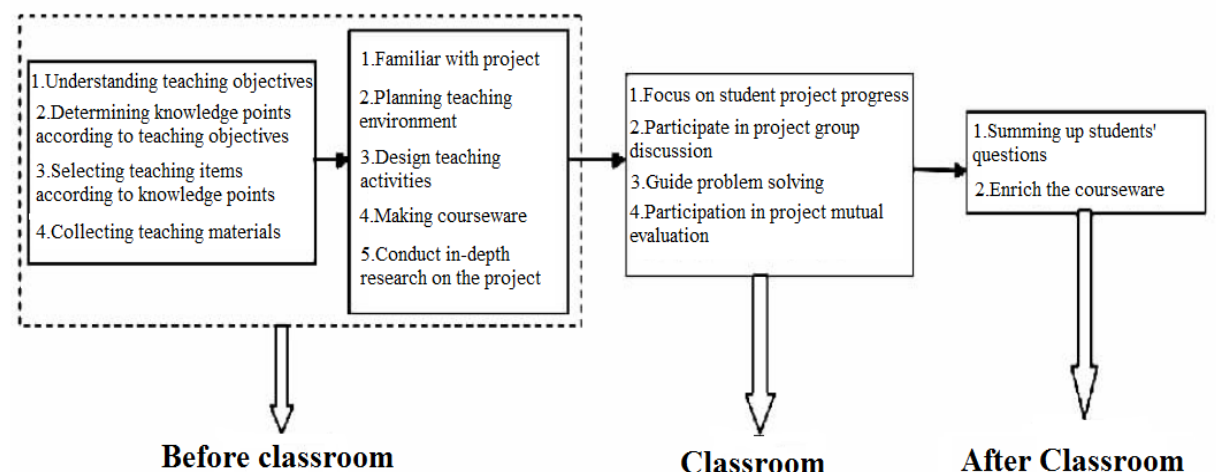

Figure 2. Teachers' teaching process structure

In traditional teaching mode, teachers should teach theoretical knowledge in class. Teachers can propose a theme for each class, and then prepare teaching content around this theme. In class, teachers can control the rhythm and content of teaching. This teaching method does not take the individual needs of students into account. It is difficult to arouse students' interest in learning, and it is easy to make the teaching content divorced from the actual situation.

In the project-based teaching integrated with the flipped classroom, students understand the theoretical knowledge which they need to master through the courseware before class. Before the beginning of the course, teachers should firstly clarify their teaching objectives, formulate syllabus and identify knowledge points. For project-based teaching, teachers need to reprocess existing teaching materials according to their understanding of knowledge points in practical application process. It requires teachers to have a broad and in-depth understanding of all the basic knowledge involved in the teaching content and the whole production process. Through project-based teaching, students can be exposed to real or simulated work world and learn to work out the basic methods of solving problems according to their own experience.

In the project-based teaching integrated with the flipped classroom, teachers do not need to think too much about the allocation of teaching time for theoretical teaching and practical operation in the classroom. Teachers can include all the knowledge involved in the courseware. The teacher can list the learning tasks and learning 
Fan / Research on Oral English Flipped Classroom Project-based Teaching Model...

contents of the project on the front page of each project. Through computer-aided tools, simple explanations will be made into presentations, abstract and difficult-to-understand contents will be made into animations, and demonstration content will be recorded into video. The teaching contents are vividly presented by means of manuscript demonstration, animation display and live video, which are made into courseware according to the teaching order. And then teachers can upload them to the network. It will make the knowledge points needed to learn become intuitive, vivid and interesting.

In addition, because the flipped classroom is a process of knowledge imparting through teaching courseware, with the popularity of the network, teachers can also use various resources on the network to enrich teaching courseware. In order to ensure that the courseware can meet the teaching content and students' acceptance progress, teachers inevitably have to edit those ready-made network materials. They can add appropriate explanations in appropriate places to make the teaching content easy to understand. In short, the content of teaching courseware should be consistent with the teaching objectives and classroom training content, and it must be able to explain new knowledge points clearly and concisely.

Students have generally understood the knowledge points involved in the teaching project by watching the courseware before class. It can be said that students come to the classroom with confidence in the basic understanding of knowledge points, with curiosity about the process of operation and practice, and with puzzlement about some difficult problems. The main task of classroom teaching is to enable students to participate in project practice by using the knowledge before class. Therefore, the selected specific practical projects should be based on the teaching tasks. They should not only contain basic teaching knowledge points, but also fully mobilize the enthusiasm of students to solve practical problems.

At the end stage of classroom teaching, teachers should summarize the problems that students are prone to occur in each teaching project, consult relevant materials for the problems and make a detailed study of them. And then teachers should enrich the relevant contents into the teaching courseware, so that the contents of the teaching courseware are more extensive and in-depth.

The students' learning process structure is shown in Figure 3.

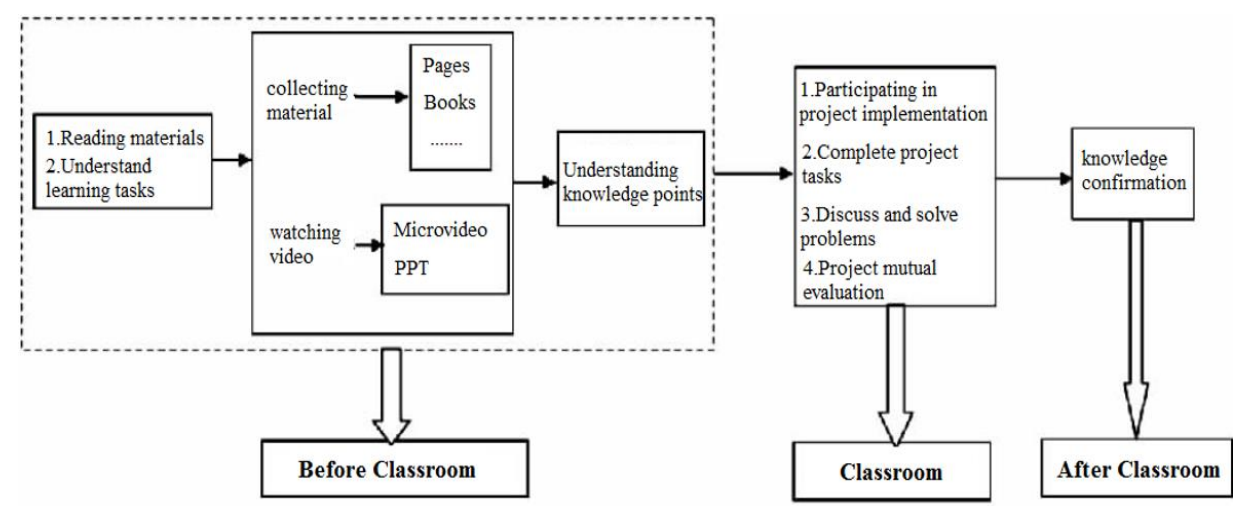

Figure 3. Students' learning process structure

For students, the project-based teaching integrated with the flipped classroom requires students to take the 
Fan / Research on Oral English Flipped Classroom Project-based Teaching Model...

$\overline{\text { initiative before class and actively engage in the learning of new knowledge. If students hear the concepts they }}$ have not touched or the theoretical contents they can not understand during the course of watching the courseware, they can stop the courseware and use the network resources with questions to find the introduction materials of the concepts or the materials for further elaboration of the theoretical contents. If students still have problems that they can't understand by looking up materials and watching courseware, they can record the problems and discuss them with their classmates or teachers in class. Pre-class preparation stage is the cornerstone of the whole flipped classroom teaching, it determines whether the subsequent learning can proceed smoothly.

In the specific implementation process of the project, students may also encounter unpredictable problems when completing their respective tasks, the problems cannot be solved by one person alone. At this time, other members of the project team need to be gathered together to discuss and study together, negotiate and solve the problems. The process of cooperative solving problem can stimulate students' desire to explore, and improve their communication skills and cultivate students' cooperative spirit.

In the pre-class stage, when students watch the courseware, their understanding of some problems may just stay on the surface and not fully understand its connotation. By personally participating in the completion process of teaching projects in the classroom, students can get in touch with every link in the workflow. The project-based teaching integrated with the flipped classroom also provides a platform for discussion and communication for students. After the completion of the project, teachers should organize students to conduct project mutual evaluation.

After completing the understanding and discussion of knowledge in the classroom, it is necessary to summarize the knowledge learned in the classroom after class. The knowledge will be consolidated in the process of summarizing, reflecting and evaluating.

\section{Conclusion}

Project-based teaching enables students to experience the process of using knowledge and skills in class, it makes students learn to explore and realize the construction and transfer of knowledge. However, project-based teaching contains more teaching contents than traditional classroom teaching, it makes the classroom time very tense. Project-based teaching integrated with flipped classroom makes full use of abundant network resources in advanced information environment so that students can complete the process of imparting knowledge and skills through independent learning of teaching courseware before class, and it can reserve sufficient time for project practice in class. Cooperative learning enables learners to actively participate in learning and accomplish learning tasks in a positive atmosphere of mutual encouragement and inspiration. The combination of the three methods will fully mobilize students' enthusiasm for participation and ensure that their learning can be completed smoothly. 


\section{References}

Chen, W., Burry-Stock, J. A., \& Rovegno, I. (2000). Self-evaluation of expertise in teaching elementary physical education from constructivist perspectives. Journal of Personnel Evaluation in Education, 14(1), 25-45. http://dx.doi.org/10.1023/a:1008138129634

Gilboy, M. B., Heinerichs, S., \& Pazzaglia, G. (2015). Enhancing student engagement using the flipped classroom. Journal of Nutrition Education \& Behavior, 47(1), 109-114. http://dx.doi.org/10.1016/j.jneb.2014.08.008

Herreid, C. F., \& Schiller, N. A. (2013). Case study: case studies and the flipped classroom. Journal of College Science Teaching, 42(5), 62-67. http://dx.doi.org/10.4108/el.1.3.e1

Mclaughlin, J. E., Roth, M. T., Glatt, D. M., Gharkholonarehe, N., Davidson, C. A., \& Griffin, L. M. (2014). The flipped classroom: a course redesign to foster learning and engagement in a health professions school. Academic Medicine Journal of the Association of American Medical Colleges, 89(2), 236-43. http://dx.doi.org/10.1097/ACM.0000000000000086

Nelson, B. (1996). Cooperative learning. Science Teacher, 63(4), 22-25. http://dx.doi.org/10.3102/00346543050002315

Pu, Z. H., Zhang, Y. J., Fang, C. H., \& Zhi, L. (2017). Research on the teaching mode of power cable course based on the hybrid flipped classroom. Education Teaching Forum, (29), 144-145.

Stephen Silverman. (2011). Teaching for student learning in physical education. Journal of Physical Education Recreation \& Dance, 82(6), 29-34. http://dx.doi.org/10.3102/10.1080/07303084.2011.10598642

Stephen, S. (1992). Cooperative learning. Education Research Consumer Guide, 50(4), 1-3. http://dx.doi.org/10.3102/00346543050002315

Teng, C. C., \& Luo, Y. P. (2015). Effects of perceived social loafing, social interdependence, and group affective tone on students' group learning performance. The Asia-Pacific Education Researcher, 24(1), 259269. http://dx.doi.org/10.1007/s40299-014-0177-2

Turnbull, M. (2010). Multidimensional project-based teaching in French second language (FSL): A processproduct case study. Modern Language Journal, 83(4), 548-568. http://dx.doi.org/10.1111/0026-7902.00040 